\title{
De-Intensification Of Blood Glucose Lowering Medication In People Identified As Being Over-Treated: A Mixed Methods Study
}

This article was published in the following Dove Press journal: Patient Preference and Adherence

\section{Huberta $E \operatorname{Hart} \mathbb{D}^{1,2, *}$ \\ Kim Ditzel ${ }^{1} * *$ \\ Guy E Rutten (1D) \\ Esther de Groot $\mathbb{D}^{\prime}$ \\ Samuel Seidu ${ }^{3}$ \\ Kamlesh Khunti $\left.{ }^{3}\right)^{3}$ \\ Rimke C Vos $\mathbb{D}^{1,4}$}

'Julius Center for Health Sciences and Primary Care, University Medical Center, Utrecht University, Utrecht, The Netherlands; ${ }^{2}$ Leidsche Rijn Julius Health Centers, Utrecht, The Netherlands; ${ }^{3}$ Diabetes Research Centre, University of Leicester, Leicester General Hospital, Leicester, UK; ${ }^{4}$ Department of Public Health and Primary Care/lumc-Campus the Hague, Leiden University Medical Center, The Hague, The Netherlands

*These authors contributed equally to this work
Correspondence: Huberta E Hart Julius Center for Health Sciences and Primary Care, University Medical Center Utrecht, Erasmuslaan 68, Zeist 3707 ZE,

The Netherlands

Tel +3I 616950844

Email h.e.hart@umcutrecht.nl
Aim: To evaluate if, one year after notification of possible overtreatment, diabetes care providers de-intensified glucose-lowering medications and to gain insight into the opinions and beliefs of both care providers and patients regarding de-intensification.

Methods: Mixed methods using routine care data from five health-care centres in the Netherlands. Patient characteristics and medication prescription of patients, previously identified as possibly over-treated, were extracted from patients' medical records. Opinions of care providers were obtained through interviews. Patients received questionnaires about their diabetes treatment and were asked to participate in focus groups.

Results: A total of 64 elderly patients with type 2 diabetes were previously identified as possibly over-treated and included; $57.8 \%$ male, median age 75 years (IQR=72-82), median diabetes duration 12 years ( $\mathrm{IQR}=8-18)$. De-intensification was implemented in more than half $(n=36)$ of them. Care providers preferred person-centred care above just setting general HbAlc target values, considering patient characteristics (such as comorbidity) and patient's preference. Patients valued glucose levels as most important in determining their treatment Both patients and care providers felt that de-intensification should occur gradually.

Conclusion: Treatment had been de-intensified in more than half of the patients $(56.3 \%)$. Insight in reasons for not de-intensifying elderly patients is important since treatment for them can be "person-centred care". De-intensification is an iterative and time-intensive process.

Keywords: elderly, overtreatment, hypoglycaemia, insulin therapy, primary care, type 2 diabetes

\section{Introduction}

Intensive glycaemic control has been proven to be beneficial in preventing microvascular and macrovascular complications in people with type 2 diabetes mellitus (T2DM). ${ }^{1,2}$ However, hypoglycaemia, particularly in the elderly, leads to significantly more doctor visits, falls and hospitalisations. ${ }^{3-5}$ Severe hypoglycaemia has also been associated with adverse outcomes such as vascular events and death. ${ }^{6-9}$

In light of this evidence, recent updated guidelines recommend a less stringent glycaemic control for older patients with T2DM. ${ }^{10}$ The Dutch College of General Practitioners (NHG) also included in their revised guideline from 2013, a more individualised algorithm to determine the glycated haemoglobin ( $\mathrm{HbA1c}$ ) target by considering the type of prescribed glucose-lowering medication, disease duration and age of the patient. This algorithm shows that patients aged $<70$ years and those aged $\geq 70$ years 
treated with a lifestyle advice only or with metformin monotherapy should achieve an $\mathrm{HbAlc}$ target $\leq 7 \%$ (53 $\mathrm{mmol} / \mathrm{mol})$. Patients above 70 years who are using more blood glucoselowering agents than metformin only and with a diabetes duration less than 10 years should achieve an $\mathrm{HbA} 1 \mathrm{c} \leq 7.5 \%$ $(58 \mathrm{mmol} / \mathrm{mol})$, those with a diabetes duration above 10 years have a target $\leq 8 \%$ (64 mmol/mol). (Figure 1). ${ }^{12}$ However, studies performed across Europe and in the United States have shown that many older patients with T2DM are overtreated according to these guidelines. The proportion of people over-treated ranges from $11 \%$ to nearly two-thirds of study populations. ${ }^{13-19}$ The failure to de-escalate treatment when clinical need is required has recently been defined as therapeutic inertia. $^{20}$

An important concept included in the position statements by the European Association for the Study of Diabetes and the American Diabetes Association (EASD/ADA) is that of a "person-centred approach" to diabetes care, defined as "providing care that is respectful of and responsive to individual patient preferences, needs and values and ensuring that patient values guide all clinical decisions". ${ }^{11}$ Consequently, treatment should not only be based on HbAlc levels but also on the patient's context and other patient characteristics, as is confirmed in the latest EASD/ADA consensus. ${ }^{21}$ This implicates that any HbAlc target is a mutual decision agreed upon by patient and physician. ${ }^{22}$ For example, a vital patient aged 72 years old could decide with his physician to strive for an HbAlc $\leq 53 \mathrm{mmol} / \mathrm{mol}$. This would mean that, according to the Dutch algorithm, the patient is over-treated, yet the patient and his physician have deliberately deviated from this target value. We previously demonstrated that approximately $40 \%$ of

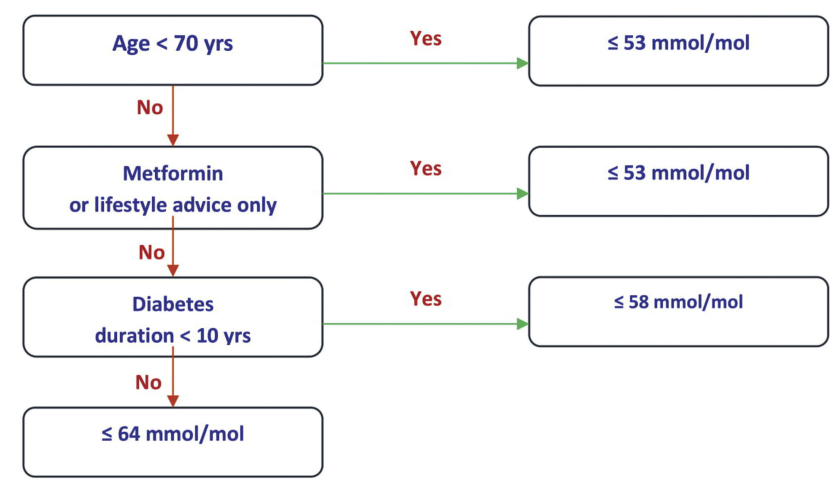

Figure I Algorithm to set the HbAlc target (Dutch diabetes guideline). This algorithm shows that patients aged $<70$ years and those aged $\geq 70$ years treated with a lifestyle advice only or with metformin monotherapy should achieve an $\mathrm{HbAlc}$ target $\leq 7 \%(53 \mathrm{mmol} / \mathrm{mol})$. Patients above 70 years who are using more blood glucose-lowering agents than metformin only and with a diabetes duration less than 10 years should achieve an $\mathrm{HbAlc} \leq 7.5 \%(58 \mathrm{mmol} / \mathrm{mol})$, those with a diabetes duration above 10 years have a target $\leq 8 \%(64 \mathrm{mmol} / \mathrm{mol})$. the patients aged $\geq 70$ years from a primary care population were over-treated, meaning that patients with a personalised $\mathrm{HbA} 1 \mathrm{c}$ target of 58 or $64 \mathrm{mmol} / \mathrm{mol}$ reached an $\mathrm{HbAlc}<53$ $\mathrm{mmol} / \mathrm{mol}$ (Figure 1). ${ }^{23}$ Amongst these patients, half of them could be considered vulnerable to the potential harm of intensive treatment if they were frail, had several comorbidities, polypharmacy and/or used sulphonylureas or insulin with their associated risks of hypoglycaemia. Based on these findings, the treating general practitioners (GPs) and practice nurses (PNs) were notified of the possible overtreatment of their patient and encouraged to re-evaluate their glucose-lowering therapy.

We aimed to evaluate if, one year after the notification of possible overtreatment glucose-lowering medication had been de-intensified. A further objective was to gain insight into the opinions and beliefs of GPs, PNs and patients regarding de-intensification of glucose-lowering medication.

\section{Methods}

\section{Study Setting And Design}

This observational study, using mixed methods, was conducted among diabetes care providers and among individuals aged $\geq 70$ years with $\mathrm{T} 2 \mathrm{DM}$ from 5 academic primary care centres in the Netherlands, who were previously identified as being possibly over-treated for their T2DM, meaning that patients with a personalised HbA1c target of 58 or $64 \mathrm{mmol} / \mathrm{mol}$ reached an HbAlc $<53$ $\mathrm{mmol} / \mathrm{mol}$ (Figure 1). ${ }^{23}$ After this study, all treating GPs and PNs were notified of the possible overtreatment of their patients and suggested to assess and discuss with their patients if de-intensification of treatment was required.

\section{Data Collection And Variables}

Patient characteristics (sex, age), duration of diabetes and HbA1c in 2017 (index period) were extracted from electronic medical records (EMR) in April 2018. If patients had moved or were deceased during the index period, data were collected and censored to that moment.

Data regarding current treatment were collected from the EMR. A manual search was performed to assess any change of glucose-lowering medication, including reasons for change. De-intensification of treatment was defined as discontinuing or lowering the dosage of any glucose-lowering medication during the index period, including changing to another agent with less risk of hypoglycaemia. The 
HbA1c target value as defined upon data from 2016 by Hart et al was maintained and the same definitions for "on target", "overtreatment" and "under-treatment" were used, as well as the definitions for polypharmacy and frailty. ${ }^{23}$

Any episode of hypoglycaemia, rebound hyperglycaemia, hyperglycaemic hyperosmolar non-ketotic coma (HONK) and diabetic ketoacidosis (DKA) were manually retrieved from the EMR, as well as falls and out-of-hours GP service and emergency room visits. Any record of experiencing complaints due to a low blood glucose was defined as presence of hypoglycaemia.

Data were collected 12 months following provision of feedback to the diabetes care providers regarding possible overtreatment.

\section{Opinions Of General Practitioners - Interviews}

The opinions of GPs regarding de-intensification were assessed by semi-structured interviews, conducted by one author (KD). Topics discussed, as listed by the research team, included facilitators and barriers in the management of elderly patients with T2DM and the received notification of possible overtreatment (Appendix A; Table A.1). GPs and PNs, with at least one possibly over-treated elderly, from each centre were invited for an interview, when four GPs and four PNs participated. Six of them were female. They received a gift voucher of $€ 50$, for their participation, but were not notified of this prior to the study.

\section{Opinions Of Patients - Focus Groups And Questionnaires}

Patients beliefs about their glucose-lowering medication were assessed with the validated Beliefs About Medicine Questionnaire specific (BMQ-S) questionnaire; patients were instructed to answer these questions for their glucose-lowering medication. ${ }^{24}$ The ten questions can be divided into five questions regarding concern and five regarding the necessity of their medication. The response is given on a five-point Likert scale, ranging from "strongly disagree" (zero points) to "strongly agree" (five points). The subtotal of the responses for the questions about concern (0-20) and necessity (0-20) was calculated, after which patients were divided into four validated categories regarding their beliefs about their medications: 1) acceptant, 2) ambivalent, 3) sceptic or 4) indifferent. Furthermore, patients were asked to answer questions (self-designed) regarding their wish to (de)intensify their treatment and the occurrence of adverse effects.

To gain more insight in patients' opinions, they were asked to participate in a focus group applying purposive sampling (Appendix A; Table A.2). Participants of the focus group received a gift voucher of $€ 25$, of which they were not notified on forehand, and restitution of travel costs. In total, seven patients participated in a focus group. There were two focus groups, with, respectively, two and five patients.

\section{Analysis}

Differences in disease characteristics between patients in whom de-intensification took place and those in whom it did not, were analysed using descriptive statistics, using IBM SPSS statistics 24; continuous data were analysed using the Mann Whitney $U$ test and categorical data using Pearson's chi squared test or Fisher's exact test as appropriate. A p-value of $<0.05$ was considered statistically significant.

For comparative analysis of the qualitative data, NVivo 11 was used. The interviews and focus groups were recorded and a transcript was obtained through an external agency. The first two interviews were coded together by KD and $\mathrm{HEH}$. The same two interviews were independently assessed by EdG. Since no major discrepancies were found, the other interviews and focus groups were assessed by KD. After coding, common themes were identified.

\section{Results}

Out of 1002 patients with T2DM, 319 were $\geq 70$ years, of whom $64(20.1 \%)$ were identified as being eligible for deintensification. More than half of them were men (57.8\%), with a median age of 75 years $(\mathrm{IQR}=72-82)$ and median diabetes duration of 12 years $(\mathrm{IQR}=8-18)$. Most patients used oral glucose-lowering medication, mainly metformin (70.3\%) and/or sulphonylureas (64.1\%) and 20.3\% used insulin. During the period between the recommendations and second data collection, 5 of the 64 possibly overtreated patients deceased (7.8\%). Two patients moved and switched to a different GP during the research period.

\section{De-Intensification Of Treatment}

Median HbA1c was $51 \mathrm{mmol} / \mathrm{mol}(\mathrm{IQR}=48-55)$. In 36 of the 64 patients $(56.3 \%)$, the dosage or number of hypoglycaemic medications were lowered. Patients whose therapy was deintensified, significantly more often used sulphonylureas $(p=0.04)$ and were more often known with comorbidity than those who maintained or even intensified their treatment 
$(p=0.01)$. Other patient characteristics were not significantly different between these two groups (Table 1). The dosage of sulphonylureas was most often decreased $(n=8)$ or stopped $(n=15)$. Insulin dose was lowered in seven patients, of whom one could completely stop using insulin (Table 2). Reasons for de-intensification were mainly because of low glucose or HbA1c values $(n=31)$ and/or the occurrence of adverse effects $(n=6)$. Although de-intensification took place, still more patients in the de-intensification group were over-treated at the end of the follow-up period compared to the other group ( $p=0.01)$. In line with that, more patients were on target in the group of patients were no de-intensification took place $(p=0.03)$. In the group were therapy was not de-intensified, the rise in HbAlc was higher than the group were de-intensification did take place, although not statistically significant $(\mathrm{p}=0.05)$.

\section{Intensification Of Treatment}

In 8 out of 36 patients whose treatment therapy initially was de-intensified, therapy was then again intensified due to a sharp rise of HbAlc or glucose values above their original personalised $\mathrm{HbA} 1 \mathrm{c}$ target or due to complaints of hyperglycaemia; in six, the sulphonylureas or insulin were resumed or the dosage intensified, in two the metformin dosage was increased. In five other patients, treatment was initially intensified, but could then afterwards be deintensified.

\section{Adverse Events}

There were no significant differences in the occurrence of adverse events in patients whose therapy had been deintensified, compared to those in whom therapy had not been de-intensified (Table 2). There was no occurrence of HONKs or DKAs.

\section{Opinions Of Care Professionals - Interviews}

All interviewed GPs and PNs indicated that they did take the recommendation in consideration and re-evaluated therapy for their patients or were planning to do so. They were positive about the three different target values and mentioned that patients (in most cases) were pleased if therapy could be de-intensified. However, they indicated that they sometimes deliberately decided on strict glycaemic control, taking different factors into account.

\section{Factors Influencing Treatment Choices}

Factors that care providers considered important were biomedical (comorbidity, having complications, life expectancy and the "biological age" of the patient) as well as social and contextual (culture and social network), the latter also

Table I Baseline Characteristics

\begin{tabular}{|c|c|c|c|}
\hline & $\begin{array}{l}\text { No De-Intensification Of Treatment } \\
(n=28)\end{array}$ & $\begin{array}{l}\text { De-Intensification Of Treatment } \\
(n=36)\end{array}$ & p-value \\
\hline & $\mathbf{N}(\%)$ & $\mathbf{N}(\%)$ & \\
\hline Age $(\text { years })^{\mathrm{a}}$ & $75.0(72.0-82.8)$ & $76.5(72.3-82.0)$ & 0.7 \\
\hline Sex (male) & $19(67.9)$ & $18(50.0)$ & 0.15 \\
\hline Diabetes duration (years) ${ }^{\mathrm{a}}$ & $12.5(6.3-18.0)$ & $12.0(8.3-16.8)$ & 0.95 \\
\hline $\begin{array}{l}\mathrm{HbAlc} \text { at start of index period } \\
(\mathrm{mmol} / \mathrm{mol})^{\mathrm{a}}\end{array}$ & $48.5(44.0-50.8)$ & $47.0(45.0-50.0)$ & 0.84 \\
\hline Target $\mathrm{HbAlc}<58 \mathrm{mmol} / \mathrm{mol}$ & II (39.3) & $12(33.3)$ & 0.62 \\
\hline Target $\mathrm{HbAlc}<64 \mathrm{mmol} / \mathrm{mol}$ & $17(60.7)$ & $24(66.7)$ & 0.62 \\
\hline Macrovascular complications & $8(28.6)$ & $9(25.0)$ & 0.75 \\
\hline Microvascular complications ${ }^{\mathrm{b}}$ & $10(52.6)$ & $13(52.0)$ & 0.97 \\
\hline Comorbidity & $7(25.0)$ & $20(55.6)$ & 0.01 \\
\hline Deceased & $3(10.7)$ & $2(5.6)$ & 0.65 \\
\hline Polypharmacy ${ }^{c}$ & $14(50.0)$ & $24(66.7)$ & 0.18 \\
\hline Living alone & $9(32.1)$ & $10(27.8)$ & 0.71 \\
\hline Frailty index $>0.2$ & $16(57.1)$ & $23(63.9)$ & 0.58 \\
\hline Sulphonylureas & $14(50.0)$ & $27(75.0)$ & 0.04 \\
\hline Insulin monotherapy & I (3.6) & $2(5.6)$ & I \\
\hline Oral therapy + insulin & $5(17.9)$ & $6(16.7)$ & 0.9 \\
\hline
\end{tabular}

Notes: a Median (interquartile range); ${ }^{\mathrm{b}}$ Twenty missing cases (missing data regarding microvascular complications in index period); ${ }^{\mathrm{C}} \mathrm{Use}$ of five or more medications. 
Table 2 Results, Adjustments And Possible Adverse Events Of Diabetes Treatment

\begin{tabular}{|c|c|c|c|}
\hline & $\begin{array}{l}\text { No De-Intensification Of } \\
\text { Treatment }(n=28)\end{array}$ & $\begin{array}{l}\text { De-Intensification Of } \\
\text { Treatment }(n=36)\end{array}$ & p-Value \\
\hline & $\mathbf{N}(\%)$ & $\mathbf{N}(\%)$ & \\
\hline $\mathrm{HbAlc}$ at end of index period $(\mathrm{mmol} / \mathrm{mol})^{\mathrm{a}}$ & $54.5(47.5-57.8)$ & $51.0(48.0-55.0)$ & 0.12 \\
\hline Difference in $\mathrm{HbAla} \mathrm{c}^{\mathrm{a}, \mathrm{b}}$ & $6.5(3.3-9.5)$ & $3.0(-1.0-7.0)$ & 0.05 \\
\hline Over-treated $^{c}$ & $9(37.5)$ & $25(71.4)$ & 0.01 \\
\hline On target ${ }^{c}$ & $12(50.0)$ & $8(22.9)$ & 0.03 \\
\hline Undertreated $^{c}$ & $3(12.5)$ & $2(5.7)$ & 0.36 \\
\hline \multicolumn{4}{|l|}{ Lowering of: } \\
\hline - Sulphonylureas ${ }^{d}$ & - & $23(85.2)$ & - \\
\hline - Insulin ${ }^{d}$ & - & $7(87.5)$ & - \\
\hline - Other glucose lowering medication ${ }^{d}$ & - & $6(22.2)$ & - \\
\hline Intensification of treatment & $10(35.7)$ & $13(36.1)$ & 0.97 \\
\hline Hypoglycaemia & $5(17.9)$ & $9(25.0)$ & 0.49 \\
\hline Fall incidents & $6(21.4)$ & $8(22.2)$ & 0.94 \\
\hline $\begin{array}{l}\text { Out-of-hours general practitioners service } \\
\text { visit }\end{array}$ & $5(17.9)$ & $5(13.9)$ & 0.66 \\
\hline Emergency room visit & $5(17.9)$ & $10(27.8)$ & 0.35 \\
\hline HONK/DKA ${ }^{\mathrm{e}}$ & $0(0)$ & $0(0)$ & - \\
\hline
\end{tabular}

Notes: a Median (interquartile range); ${ }^{b}$ Difference in HbAlc (end of index period - start of index period); ${ }^{c}$ Five missing cases; ${ }^{\mathrm{d}} \%$ of total patients in the de-intensification

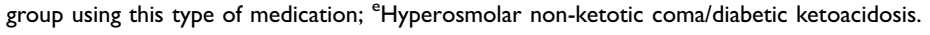

involved the capacity of a patient to control glucose values themselves. They stated also to look at lifestyle, for example, if a patient has an active lifestyle. Furthermore, diabetes care providers took the occurrence of adverse effects, mainly hypoglycaemia, into account and stated that they thought of the possible benefits of a strict glycaemic control, namely preventing complications.

If someone is in a nursing home with food being brought to them at regular times, then that's a safer situation than when someone is alone at home.

[...] a patient who has heart failure (amongst other things) and is at risk for developing wounds. Then I think to myself, her glucose value is easily manageable. [...] If she develops a complication such as a wound, then at least she's better regulated (author: in order to heal faster).

\section{Person-Centred Care}

In line with considering these patient characteristics, the concept of person-centred care was brought forward by several care providers. Striving for person-centred care may mean deviating from the HbAlc target values, which are based on age, prescribed medication and duration of disease. The consensus was that person-centred care was valued to be the most important.
In the end we are treating patients, not numbers.

You know, protocols for the care of patients with diabetes have brought us a lot [..]. But in the end, you have to make the translation back to personal care and to what this patient needs.

\section{De-Intensification Is A Time-Consuming Process}

De-intensification of treatment in patients with T2DM was considered a time-consuming process. De-intensifying medication takes place in small steps.

Using day-time glucose values, you first may consider which dosage of fast working insulin could be diminished, very carefully, with 2 international units of insulin at a time.

A less strict glycaemic target requires a change in treating mentality for care providers. For most of them, more awareness of the possibility of overtreatment was created during the previous study. They experienced that the patients are often used to a tight glycaemic control and that they sometimes have a problem letting this go. The care providers considered it complicating that glucoselowering medication was sometimes intensified after a visit to specialists. 
Yes, it is interesting, because I never thought of it that way. We are always focused on more stringent control. It is a good wake-up call, that you can also think of it the other way around.

As a practical limitation, it was mentioned that stopping a sulphonylurea could result in a change in target values according to the algorithm of the Dutch guidelines - leaving the patient on metformin monotherapy with the connected $\mathrm{HbAlc}$ target of $\leq 53 \mathrm{mmol} / \mathrm{mol}$ - after which a person with the same HbAlc value could then be undertreated.

Then you are going to check which target value someone has, which is now the one without sulphonylureas (author: after discontinuing sulphonylureas), which means that he/ she is under treated. [...] So, you keep going back and forth. (author: between target values).

\section{Patients' Opinions And Beliefs}

Thirty-six patients returned the questionnaires (Appendix B). Only six reported that change of treatment had been discussed with them; in four of these patients, medication had been changed. When asked if they would like their glucose to be regulated differently (less strict or stricter, without discussing this with their GP), $70.6 \%$ of the respondents did not want to change and $26.5 \%$ stated to prefer less strict treatment, whereas $2.9 \%$ preferred stricter glycaemic control.

\section{Beliefs About Medication}

Based on the BMQ-S, almost half of the patients (44.4\%) were indifferent regarding their medication intake, meaning they had low concerns and saw little necessity of taking their glucose-lowering medication. More than one in three were ambivalent (36.1\%); they had high concerns and regarded the necessity of their glucose-lowering medication as high. The vast majority (96.4\%) experienced no adverse effects, $7.8 \%$ had no clear opinion in this respect and six (16.7\%) did report adverse effects. Out of the six patients reporting adverse effects, four patients had their therapy de-intensified.

\section{Main "Patient-Themes"}

The participants of the focus groups (see Table 3) were satisfied with the current way their diabetes was managed. They found the decision regarding their treatment to be a mutual one but considered the care professional as the expert. The main themes regarding their diabetes treatment were medication use, glucose levels and adverse effects. They thought the glucose level was most important in their choice
Table 3 Characteristics Of Patients, Participating In Focus Groups

\begin{tabular}{|l|l|l|}
\hline Patient Characteristics & N (\%) & $\begin{array}{l}\text { Median } \\
\text { (Interquartile } \\
\text { Range) }\end{array}$ \\
\hline $\begin{array}{l}\text { Sex } \\
\text { Male }\end{array}$ & $4(57.1)$ & \\
\hline Age (years) & & $77.0(75.0-84.0)$ \\
\hline $\begin{array}{l}\text { Ethnicity } \\
\text { Western-European }\end{array}$ & $5(71.4)$ & \\
\hline Noroccan & $\mathrm{I}(14.3)$ & \\
\hline $\begin{array}{l}\text { Diabetes duration (years) } \\
\text { Living alone }\end{array}$ & $\mathrm{I}(14.3)$ & $13.0(6.0-27.0)$ \\
\hline $\begin{array}{l}\text { HbAlc target } \\
58 \text { mmol/mol } \\
64 \text { mmol/mol }\end{array}$ & $2(28.6)$ & \\
\hline $\begin{array}{l}\text { HbAlc value (mmol/mol) } \\
\text { De-intensification of therapy }\end{array}$ & $4(57.1)$ & $4(57.1)$ \\
$\begin{array}{l}\text { Frailty index > 0.2 } \\
\text { Hypoglycaemia }\end{array}$ & $2(28.6)$ & \\
$\begin{array}{l}\text { Fall incidents } \\
\text { Out-of-hours general practice } \\
\text { service visit } \\
\text { Emergency room visit }\end{array}$ & $0(0)$ & \\
\hline
\end{tabular}

of therapy. Changes in medication (type and/or dosage) can cause uncertainty. When asked about hypoglycaemia, most participants stated not to be afraid of having it, because it was explained well to them and they recognised the signs.

If the glucose value isn't good in the long term, it's not going well. You choose what's best to live a healthy life for as long as possible.

Then the dosage is halved, and then it goes back to the full dosage again. Then I think to myself, what is the right thing to do?

When asked about the possibility of de-intensification of therapy, most patients would consider that mainly because they would like to take less medications. However, there were questions about the reasoning behind this deintensification.

If I could take less medication, I would say [agreeing sound]. But I think it's weird, [...], that they're now telling it (author: the HbAlc value) can be higher. Is this a result from research? 


\section{Discussion}

This study shows that de-intensification of glucose-lowering medication occurred in more than half of the patients (56.3\%), one year after detection of possible overtreatment. This is more than in previously published studies, with percentages ranging from $9.6 \%$ to $17.5 \%{ }^{14,25,26}$ and could be explained by the fact that in two of these studies no notification of possible overtreatment was used. ${ }^{14,25}$ Another possibility is the latter studies were conducted between 2011 and 2014 before individualising treatment target was recommended in international guidelines. ${ }^{13-18,23}$ Patients whose therapy was de-intensified were significantly more often known with comorbidity than those who maintained or even intensified their treatment and more often used sulphonylureas. This suggests that the care providers took the type of hypoglycaemic medication and the presence of comorbidity, polypharmacy and frailty into account when deciding about whether or not to de-intensify, a decision which can be supported be recent evidence. ${ }^{27,28}$

However, at the end of our follow-up period significantly more patients whose treatment had been de-intensified were still over-treated, compared to those in whom no de-intensification took place. There are a few possible explanations. First, health-care providers indicated that de-intensification was a time-consuming process and lowering of dosages is a stepwise process and depends on the opinions and beliefs of those involved. Furthermore, one could also state that the algorithm that defined "overtreatment" is not "holistic", as it takes only three factors into account, namely a patient's age, the diabetes duration and the blood glucose-lowering medication (Figure 1). This conclusion is in line with the GPs' and nurses' responses in the interviews that a deliberate choice for not de-intensifying treatment could have been made. It is a surprising observation that one year later, in the no deintensification group, $50 \%$ of the patients were on target and $12.5 \%$ were undertreated, which means that in $62.5 \%$ of the patients, the initial decision not to de-intensify therapy may have been appropriate, a strong argument to support the suggestion that "doctors and nurses may feel that a deliberate choice for not de-intensifying treatment could have been made". This finding also suggests that not de-intensifying could be a case of "appropriate judgement" and not of "clinical inertia. ${ }^{29-32}$ This is supported by the observations that $\mathrm{HbA} 1 \mathrm{c}$ raised more in the group where no de-intensification took place.

Indeed, from our previous study, we can conclude that, for example, the frailty index and the use of polypharmacy did not differ between people who were undertreated, on target or over-treated. ${ }^{23}$ Lastly, as already mentioned before, no longer prescribing (for example) sulphonylureas or insulin would result in a different $\mathrm{HbAlc}$ target value conform the HbAlc algorithm of the Dutch Diabetes guideline $^{12}$ (Figure 1) and a patient could be over-treated with metformin and sulphonylureas, but immediately "undertreated" with the same HbAlc level once the sulphonylurea is stopped. This underpins a further weakness of the algorithm.

The care providers who participate in the focus groups stated that person-centred care is more important than striving for the HbAlc target level from the guideline. Against that background, it is surprising that shared decision-making often does not take place or is not recognized as such by the patients. The results of the BMQ-S showed that perceptions about medications differ amongst patients, stressing again for a person-centred approach.

Although de-intensification is considered a time-consuming process, the care providers recognized the importance of de-intensification and stated an increased awareness of possible overtreatment after receiving the notification. This may be considered an improvement compared to an earlier study, in which almost half of the care providers did not see any harm in maintaining a strict $\mathrm{HbAlc}$ target value in case of an elderly individual experiencing hypoglycaemia. ${ }^{33}$

From the patients' perspective, glucose levels, the burden of medication usage, such as adverse effects, should be considered when changing glucose-lowering medication. This finding is in line with those from a systematic review. ${ }^{34}$ Another study found that patients with diabetes wanted to feel good now and in the future and agreed that sometimes strict management was necessary to achieve this. The patients in that study did report a fear of hypoglycaemia, in contrast with the patients in our focus group. ${ }^{35}$ The absence of fear of hypoglycaemia could influence their wish to (not) de-intensify their treatment.

\section{Strengths And Limitations}

This study provides further insight into the implementation of recommendations for de-intensifying glucose-lowering therapy in elderly with T2DM. By using a mixed-methods design, we obtained the opinions of care providers and the opinions and beliefs of patients. However, the study was performed in a small number of patients and diabetes care providers and not all biomedical data were available during the complete index period. Furthermore, we included 
all falls, out-of-hours general practitioners service and emergency room visits, which are not all hypoglycaemiarelated. Moreover, we described limited patient characteristics and did not mention the type of treatment of the patients included in the focus group; only one of them lived alone and only two experienced hypoglycaemia, which will have influenced their limited reported fear of hypoglycaemia.

Lastly, we used the targets for HbA1c as defined in 2016 by Hart et al. ${ }^{23}$ However, during the index period, 14 patients changed from $\mathrm{HbA} 1 \mathrm{c}$ target level due to disease duration of 10 instead of 9 years $(n=3)$ or because sulphonylureas were discontinued and patients therefore switched to the metformin monotherapy group $(n=11)$.

\section{Conclusion}

Blood glucose-lowering treatment had been de-intensified in more than half of the patients $(56.3 \%)$. De-intensifying treatment requires "person-centred care" and is a timeconsuming process which needs consideration. Care providers should engage in a conversation with their patients, explaining the benefits and harms of a (less) stringent glycaemic control, reaching a mutually agreed target level. This target level can be a deliberate deviation from the guideline, because of patient characteristics or preferences. Awareness of the potentially over-treated patient is essential to provide adequate care for these patients.

\section{Ethics}

The Medical Research Ethics Committee (METC) reviewed the study protocol and decided that the Medical Research Involving Human Subjects Act (WMO) does not apply on this study. However, all patients received patient information and gave written informed consent before entering the study.

\section{Funding}

This study was initiated and completed independently by Primary Care Diabetes Study Group of the European Association for the Study of Diabetes with full funding from Primary Care Diabetes Europe (PCDE). PCDE has received corporate gold sponsorship from Eli Lilly and Astra Zeneca and silver sponsorship from Roche.

\section{Disclosure}

KK has acted as a consultant, speaker or received grants in support for research from Amgen, Novartis, Novo Nordisk, Sanofi-Aventis, Boehringer Ingelheim, Lilly, Pfizer and Merck Sharp \& Dohme. SS has acted as consultant, advisory board member and speaker for Novo Nordisk, Amgen, SanofiAventis, Lilly, Merck Sharp \& Dohme, Boehringer Ingelheim, AstraZeneca and Janssen, NAPP and Novartis. He has received research grants from Jansen Pharm. SS and KK are supported by the NIHR Collaboration for Leadership in Applied Health Research and Care East Midlands (CLAHRC EM) and the NIHR Leicester, Biomedical Research Centre. The views expressed are those of the authors and not necessarily those of the NHS, the NIHR or the Department of Health and Social Care. GER and RCV report grants from PCDE, during the conduct of the study. RCV also reports grants from Sanofi, outside the submitted work. The authors report no other conflicts of interest in this work.

\section{References}

1. UK Prospective Diabetes Study (UKPDS) Group. Intensive bloodglucose control with sulphonylureas or insulin compared with conventional treatment and risk of complications in patients with type 2 diabetes (UKPDS 33). Lancet. 1998;352:837-853.

2. Holman RR, Paul SK, Bethel MA, Matthews DR, Neil HAW. 10-year follow-up of intensive glucose control in type 2 diabetes. $N$ Engl $J$ Med. 2008;359(15):1577-1589. doi:10.1056/NEJMoa0806470

3. Geller AI, Shehab N, Lovegrove MC, et al. National estimates of insulin-related hypoglycemia and errors leading to emergency department visits and hospitalizations. JAMA Intern Med. 2014;174 (5):678-686. doi:10.1001/jamainternmed.2014.136

4. Signorovitch JE, Macaulay D, Diener M, et al. Hypoglycaemia and accident risk in people with type 2 diabetes mellitus treated with noninsulin antidiabetes drugs. Diabetes Obes Metab. 2013;15(4):335341. doi:10.1111/dom.12031

5. Zaccardi F, Davies MJ, Dhalwani NN, et al. Trends in hospital admissions for hypoglycaemia in England: a retrospective, observational study. Lancet Diabetes Endocrinol. 2016;4(8):677-685. doi:10.1016/S2213-8587(16)30091-2

6. Majumdar SR, Hemmelgarn BR, Lin M, McBrien K, Manns BJ, Tonelli M. Hypoglycemia associated with hospitalization and adverse events in older people. Diabetes Care. 2013;36(11):3585LP-3590. doi: $10.2337 / \mathrm{dc} 13-0523$

7. Zoungas S, Patel A, Chalmers J, et al. Severe hypoglycemia and risks of vascular events and death. $N$ Engl J Med. 2010;363(15):14101418. doi:10.1056/NEJMoa1003795

8. Fitzpatrick C, Chatterjee S, Seidu S, et al. Association of hypoglycaemia and risk of cardiac arrhythmia in patients with diabetes mellitus: a systematic review and meta-analysis. Diabetes Obes Metab. 2018;20(9):2169-2178. doi:10.1111/dom.13348

9. Bonds DE, Miller ME, Bergenstal RM, et al. The association between symptomatic, severe hypoglycaemia and mortality in type 2 diabetes: retrospective epidemiological analysis of the ACCORD study. Bmj. 2010;340:b4909. doi:10.1136/bmj.b4909

10. American Diabetes Association. 11. Older adults. Diabetes Care. 2017;40(Supp11):S99-S104. doi:10.2337/dc17-S014

11. Inzucchi SE, Bergenstal RM, Buse JB, et al. Management of hyperglycaemia in type 2 diabetes: a patient-centered approach. Position statement of the American Diabetes Association (ADA) and the European Association for the Study of Diabetes (EASD). Diabetologia. 2012;55 (6):1577-1596. doi:10.1007/s00125-012-2534-0

12. Rutten GEHM, de Grauw WJC, Nijpels G, et al. NHG-standaard diabetes mellitus type 2 (derde herziening). Huisarts Wet. 2013;56 (10):512-525. 
13. Arnold SV, Lipska KJ, Wang J, Seman L, Mehta SN, Kosiborod M. Use of intensive glycemic management in older adults with diabetes mellitus. J Am Geriatr Soc. 2018. doi:10.1111/jgs.15335

14. Maciejewski ML, Mi X, Sussman J, et al. Overtreatment and deintensification of diabetic therapy among medicare beneficiaries. $J$ Gen Intern Med. 2018;33(1):34-41. doi:10.1007/s11606-017-4167-y

15. Hambling CE, Seidu S, Davies MJ, Khunti K. Older people with type 2 diabetes, including those with chronic kidney disease or dementia, are commonly overtreated with sulfonylurea or insulin therapies. Diabet Med. 2017. doi:10.1111/dme.13380

16. Dejager S, Penfornis A, Fiquet B, Blickle JF. Potential glycemic overtreatment in patients $\geq 75$ years with type 2 diabetes mellitus and renal disease: experience from the observational OREDIA study. Diabetes Metab Syndr Obes Targets Ther. 2015;8:303. doi:10.2147/DMSO.S83897

17. Lipska KJ, Ross JS, Miao Y, Shah ND, Lee SJ, Steinman MA. Potential overtreatment of diabetes mellitus in older adults with tight glycemic control. JAMA Intern Med. 2015;175(3):356-362. doi:10.1001/jamainternmed.2014.7345

18. Andreassen LM, Sandberg S, Kristensen GBB, UØ S, Kjome RLS. Nursing home patients with diabetes: prevalence, drug treatment and glycemic control. Diabetes Res Clin Pract. 2014;105(1):102-109. doi:10.1016/j.diabres.2014.04.012

19. Müller N, Khunti K, Kuss O, et al. Is there evidence of potential overtreatment of glycaemia in elderly people with type 2 diabetes? Data from the GUIDANCE study. Acta Diabetol. 2017;54(2):209214. doi:10.1007/s00592-016-0939-9

20. Khunti K, Davies MJ. Clinical inertia-time to reappraise the terminology?. Prim Care Diabetes. 2017;11(2):105-106. doi:10.1016/j. ped.2017.01.007

21. Davies MJ, D'Alessio DA, Fradkin J, et al. Management of hyperglycemia in type 2 diabetes, 2018. A consensus report by the American Diabetes Association (ADA) and the European Association for the Study of Diabetes (EASD). Diabetes Care. 2018:dci180033. doi:10.2337/dci18-0033

22. Rutten GEHM, Alzaid A. Person-centred type 2 diabetes care: time for a paradigm shift. Lancet Diabetes Endocrinol. 2018;6(4):264 266. doi:10.1016/S2213-8587(17)30193-6

23. Hart HE, Rutten GE, Bontje KN, Vos RC. Overtreatment of older patients with type 2 diabetes mellitus in primary care. Diabetes Obes Metab. 2018;20(4):1066-1069. doi:10.1111/dom.13174

24. Horne R, Weinman J. Patients' beliefs about prescribed medicines and their role in adherence to treatment in chronic physical illness. $J$ Psychosom Res. 1999;47(6):555-567. doi:10.1016/S0022-3999(99) 00057-4
25. Sussman JB, Kerr EA, Saini SD, et al. Rates of deintensification of blood pressure and glycemic medication treatment based on levels of control and life expectancy in older patients with diabetes mellitus. JAMA Intern Med. 2015;175(12):1942-1949. doi:10.1001/jamainternmed.2015.5110

26. Vimalananda VG, DeSotto K, Chen T, et al. A quality improvement program to reduce potential overtreatment of diabetes among veterans at high risk of hypoglycemia. Diabetes Spectr. 2017;30(3):211216. doi: $10.2337 / \mathrm{ds} 16-0006$

27. Lipska KJ, Krumholz H, Soones T, Lee SJ. Polypharmacy in the aging patient: a review of glycemic control in older adults with type 2 diabetes. JAMA. 2016;315(10):1034-1045. doi:10.1001/jama.2016.0299

28. Formiga F, Vidal X, Agusti A, et al. Inappropriate prescribing in elderly people with diabetes admitted to hospital. Diabet Med. 2016;33(5):655-662. doi:10.1111/dme.12894

29. Reach G, Pechtner V, Gentilella R, Corcos A, Ceriello A. Clinical inertia and its impact on treatment intensification in people with type 2 diabetes mellitusitle. Diabetes Metab. 2017;43(6):501-511. doi:10.1016/j.diabet. 2017.06.003

30. Crowley MJ, Smith VA, Olsen MK, Danus S, Oddone EZ, Bosworth HBPB. Treatment intensification in a hypertension telemangement trial. Clinical inertia or good clinical judgment. Hypertension. 2011;58 (4):552-558. doi:10.1161/HYPERTENSIONAHA.111.174367

31. Persell SD, Dolan NC, Friesema EM, Thompson JA, Kaiser DBD. Frequency of inappropriate medical exceptions to quality measures. Ann Intern Med. 2010;152(4):225-231. doi:10.7326/0003-4819-1524-201002160-00007

32. Safford M, Shewchuk R, Williams JH, Estrada CA, Ovalle FAJ. Reasons for not intensifying medications: differentiating "clinical inertia" from appropriate care. J Gen Intern Med. 2007;22(12):16481655. doi:10.1007/s11606-007-0433-8

33. Caverly TJ, Fagerlin A, Zikmund-Fisher BJ, et al. Appropriate prescribing for patients with diabetes at high risk for hypoglycemia. JAMA Intern Med. 2015;175(12):1994. doi:10.1001/jamainternmed.2015.5950

34. von Arx L-B, Kjær T. The patient perspective of diabetes care: a systematic review of stated preference research. Patient Patient Centered Outcomes Res. 2014;7(3):283-300. doi:10.1007/s40271014-0057-0

35. Svedbo Engström M, Leksell J, Johansson U-B, Gudbjörnsdottir S. What is important for you? A qualitative interview study of living with diabetes and experiences of diabetes care to establish a basis for a tailored patient-reported outcome measure for the Swedish National Diabetes Register. BMJ Open. 2016;6(3):e010249. doi:10.1136/bmjopen-2015-010249
Patient Preference and Adherence

\section{Publish your work in this journal}

Patient Preference and Adherence is an international, peer-reviewed, open access journal that focusing on the growing importance of patient preference and adherence throughout the therapeutic continuum. Patient satisfaction, acceptability, quality of life, compliance, persistence and their role in developing new therapeutic modalities and compounds to optimize clinical outcomes for existing disease states are major areas of interest for the journal. This journal has been accepted for indexing on PubMed Central. The manuscript management system is completely online and includes a very quick and fair peer-review system, which is all easy to use. Visit http:// www.dovepress.com/testimonials.php to read real quotes from published authors. 